\title{
Refuge
}

Canada's Journal on Refugees

Revue canadienne sur les réfugiés

\section{What Role Does Type of Sponsorship Play in Early Integration Outcomes? Syrian Refugees Resettled in Six Canadian Cities}

\author{
Michaela Hynie, Susan McGrath, Jonathan Bridekirk, Anna Oda, Nicole Ives, \\ Jennifer Hyndman, Neil Arya, Yogendra B. Shakya, Jill Hanley and Kwame \\ McKenzie
}

Volume 35, Number 2, 2019

Private Sponsorship in Canada

URI: https://id.erudit.org/iderudit/1064818ar DOI: https://doi.org/10.7202/1064818ar

See table of contents

Publisher(s)

Centre for Refugee Studies, York University

ISSN

0229-5113 (print)

1920-7336 (digital)

Explore this journal

Cite this article

Hynie, M., McGrath, S., Bridekirk, J., Oda, A., Ives, N., Hyndman, J., Arya, N., Shakya, Y., Hanley, J. \& McKenzie, K. (2019). What Role Does Type of Sponsorship Play in Early Integration Outcomes? Syrian Refugees Resettled in Six Canadian Cities. Refuge, 35(2), 36-52. https://doi.org/10.7202/1064818ar

\section{Article abstract}

There is little longitudinal research that directly compares the effectiveness of Canada's Government-Assisted Refugee (GAR) and Privately Sponsored Refugee (PSR) Programs that takes into account possible socio-demographic differences between them. This article reports findings from 1,921 newly arrived adult Syrian refugees in British Columbia, Ontario, and Quebec. GARs and PSRs differed widely on several demographic characteristics, including length of time displaced. Furthermore, PSRs sponsored by Groups of 5 resembled GARs more than other PSR sponsorship types on many of these characteristics. PSRs also had broader social networks than GARs. Sociodemographic differences and city of residence influenced integration outcomes, emphasizing the importance of considering differences between refugee groups when comparing the impact of these programs.
Copyright (c) Refuge: Canada's Journal on Refugees, 2019

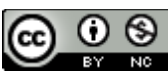

This document is protected by copyright law. Use of the services of Érudit (including reproduction) is subject to its terms and conditions, which can be viewed online.

https://apropos.erudit.org/en/users/policy-on-use/ 


\title{
What Role Does Type of Sponsorship Play in Early Integration Outcomes? Syrian Refugees Resettled in Six Canadian Cities
}

\author{
MICHAELA HYNIE, SUSAN MCGRATH, JONATHAN BRIDEKIRK, ANNA ODA, NICOLE IVES, \\ JENNIFER HYNDMAN, NEIL ARYA, YOGENDRA B. SHAKYA, JILL HANLEY, \\ KWAME MCKENZIE, and SYRIA.LTH
}

\section{Abstract}

There is little longitudinal research that directly compares the effectiveness of Canada's Government-Assisted Refugee (GAR) and Privately Sponsored Refugee (PSR) Programs that takes into account possible socio-demographic differences between them. This article reports findings from 1,921 newly arrived adult Syrian refugees in British Columbia, Ontario, and Quebec. GARS and PSRs differed widely on several demographic characteristics, including length of time displaced. Furthermore, PSRS sponsored by Groups of 5 resembled GARS more than other PSR sponsorship types on many of these characteristics. PSRs also had broader social networks than GARs. Sociodemographic differences and city of residence influenced integration outcomes, emphasizing the importance of considering differences between refugee groups when comparing the impact of these programs.

\section{Résumé}

Il existe peu de recherches longitudinales comparant directement l'efficacité des programmes gouvernemental (RPG) et privé(PPR) deparrainage des réfugiésau Canadaquitiennent compte de possibles différences socio-démographique entre eux. Cet article rend compte des résultats de 1921 nouveaux arrivants syriens adultes en Colombie-Britannique, en Ontario et au Québec. Les RPG et PPR diffèrent largement sur plusieurs caractéristiques démographiques, dont le temps du déplacement. De plus, les PPR parrainés par groupes de cinq ressemblaient davantage aux $R P G$ que les autres types de parrainage PPR sur plusieurs de ces caractéristiques. Les PPR avaient aussi des réseaux sociaux plus larges que les RPG. Les différences sociodémographiques et la ville de résidence influent sur l'intégration, ce qui fait ressortir l'importance de tenir compte des différences entre les groupes de réfugiés dans la comparaison de l'impact de ces programmes.
(C) Michaela Hynie et al., 2019. This open-access work is licensed under a Creative Commons Attribution-NonCommercial 4.0 International Licence, which permits use, reproduction, and distribution in any medium for non-commercial purposes, provided the original authorship is credited and the original publication in Refuge: Canada's Journal on Refugees is cited.
Cette ouvre en libre accès fait lobjet d'une licence Creative Commons Attribution-NonCommercial 4.0 International License, laquelle autorise l'utilisation, la reproduction et la distribution de l’euvre sur tout support à des fins non commerciales, pourvu que l'auteur ou les auteurs originaux soient mentionnés et que la publication originale dans Refuge: revue canadienne sur les réfugiés soit citée. 


\section{Introduction}

7 he number of people displaced worldwide has increased dramatically to 68.5 million over the last ten years. ${ }^{1}$ More than two thirds of refugees face protracted displacement, with the average length of exile at around ten years, and over a third of refugees in situations lasting twenty years or longer. ${ }^{2}$ Durable solutions have not kept pace with demands for protection. In 2017 only $3 \%$ of the more than 25.4 million people forcibly displaced across international borders were repatriated, locally integrated in host states, or resettled. ${ }^{3}$ The international community has been seeking new solutions to forced migration, and Canada's unique private sponsorship model has garnered significant interest. 4 The Private Refugee Sponsorship Program allows non-profit organizations and groups of citizens to financially and personally support people through their first year in Canada, ${ }^{5}$ one small additional way to contribute to the successful resettlement of refugees worldwide.

Between 4 November 2015 and 30 June 2018, Canada resettled 56,260 Syrian refugees, with almost equal numbers coming through privately sponsored and government assisted pathways. ${ }^{6}$ The ability of the Canadian government to meet its increased targets reflects one of the intended benefits of the PSR Program: it allows rapid responses to exceptional situations. 7 This article addresses the question of whether early integration benefits observed among GARs and PSRS can be attributed to pre-migration differences, or to the anticipated benefits of private settlement-specifically, potential differences in social capital between GARS and PSRS.

\section{Refugee Resettlement in Canada}

Canada provides protection to resettled refugees through three different programs. Government assisted refugees (GARs) are provided financial and settlement support for the first year of settlement through government resettlement agencies. Privately sponsored refugees (PSRs) receive financial and settlement support from non-profit organizations and volunteer groups. In the third program, Blended Visa Office-Referred (BVOR), financial support is divided between government and private sponsors, while the latter provide settlement support. ${ }^{8}$ In all categories, refugees should be offered reception, orientation, and focused assistance with housing, physical and mental health, language training, education, employment, referrals to essential federal/provincial programs and settlement programs, and financial assistance.

Private sponsors are citizens or residents who volunteer their time and money to support a refugee family or individual for one year. There are various types. Sponsorship agreement holders (sAHS) are incorporated organizations who have ongoing contractual agreements with the federal government to resettle refugees. They are frequently faithbased organizations, though they may contain subgroups that are faith or non-faith-based groups. Community sponsors are any organizations in a community that form an agreement with the government to settle refugees into their community. The program that has received the greatest attention in discussions of private sponsorship is the Group of Five (G5) sponsorship, where five or more private citizens or permanent residents (or as few as two in Quebec) ${ }^{9}$ over the age of eighteen form a sponsorship group and undertake to sponsor a refugee.

Private sponsorship has been promoted as benefitting Canada and refugees. ${ }^{10}$ More Canadian citizens have the opportunity to interact with refugee newcomers, which may promote better or broader intergroup relationships. ${ }^{11}$ In addition, refugee newcomers could achieve better settlement through private sponsorship because of the increased social capital available through their relationships with their sponsors. ${ }^{12}$ However, there is little longitudinal research that directly compares the effectiveness of the GAR and PSR Programs in supporting the integration of refugees into society.13

Research identifies stronger employment outcomes for PSRS in general. ${ }^{14}$ PSRS outperform GARS in the early years, but this relative advantage decreases over time. ${ }^{15}$ However, there are significant differences between GARS and PSRS. PSRS and GARs are selected differently: GARS on the basis of their vulnerability according to UNHCR criteria, whereas PSRS may be named by family members resident in Canada or faithbased institutions. PSRs tend to have stronger English- or French-language skills and higher levels of education, often mirroring the populations already in Canada with which they have pre-existing family or social network connections. ${ }^{16}$ They are also more likely to be single adults $(57 \%$ vs. $47 \%$ ) and thus have more mobility to pursue economic and integration activities. ${ }^{17}$ As a result, it is not clear whether better employment outcomes for PSRS can be attributed to the category and the care of sponsors or whether their resettlement outcomes are more a reflection of the very different socio-demographic profiles of two groups of sponsored refugees. ${ }^{18}$

\section{Research Design and Methods}

This article reports on the data collected in the first year of a longitudinal study on Syrian refugee integration in Canada (SyRIA.Ith). SyRIA.lth is a four-year, CIHR-funded study that compares integration outcomes for government assisted and privately sponsored refugees resettled into Canada as part of Canada's response to the Syrian conflict. The purpose of this longitudinal mixed-methods study is to compare how GAR and PSR resettlement programs in three different provinces support long-term social integration pathways for refugees 
and the impact of these pathways on physical and mental health. Ethics approval was obtained from a universityaffiliated ethics board at each research site.

\section{Theoretical Underpinning}

The theoretical underpinning of this research study and the guiding principle for the quantitative longitudinal survey reported here is the holistic integration model ${ }^{19}$ (see figure 1). The holistic integration model (HIM) is derived from the Ager and Strang model of integration ${ }^{20}$ and was developed to emphasize key issues in integration theory. These include the interrelatedness of different integration elements and the moderating effects of refugees' past experiences and social identities. A central motivation for the development of this model was also the importance of considering the larger sociopolitical context in which refugees settle. Focusing only on changes in refugee newcomers fails to acknowledge how policies, institutions, and social environments create social and structural barriers to integration. ${ }^{21}$ In emphasizing the importance of social and structural processes in the HIM, we echo calls from feminist and post-colonial scholars that concepts such as integration can result in "strategic integration" of refugees and immigrants from racialized backgrounds into "bare life" existence. ${ }^{22}$ Resettlement for racialized refugees is often marked by persistent poverty, un/ underemployment, and overrepresentation in low-income underserved neighbourhoods, conditions that mirror and deepen colonial/racialized and gendered inequalities. In the HIM the onus to integrate, adjust, and change does not fall on just refugees/immigrants but also on the dominant host society. Holistic and equitable integration requires policies and public education campaigns to help overcome colonial/ racist and xenophobic world views, policies, and socioeconomic conditions. Although our quantitative measures do not allow us to measure the more structural elements of the HIM, our analysis and discussion places the elements we are able to measure (i.e., social networks) within the broader socio-political context.

\section{Methods}

\section{Participants}

Research sites include six urban centres of varying sizes in three of the largest immigrant-receiving provinces in Canada. The aim was to enrol at least $10 \%$ of the anticipated 18,000 adult PSR and GAR arrivals between January 2016 and June 2017. A total of 1921 adult Syrian refugees representing 856 households participated in Year 1. A small number of BVORs were also included, not through purposive sampling, but because they resided in households with GARS or PSRs. Recruitment was through snowball sampling, and

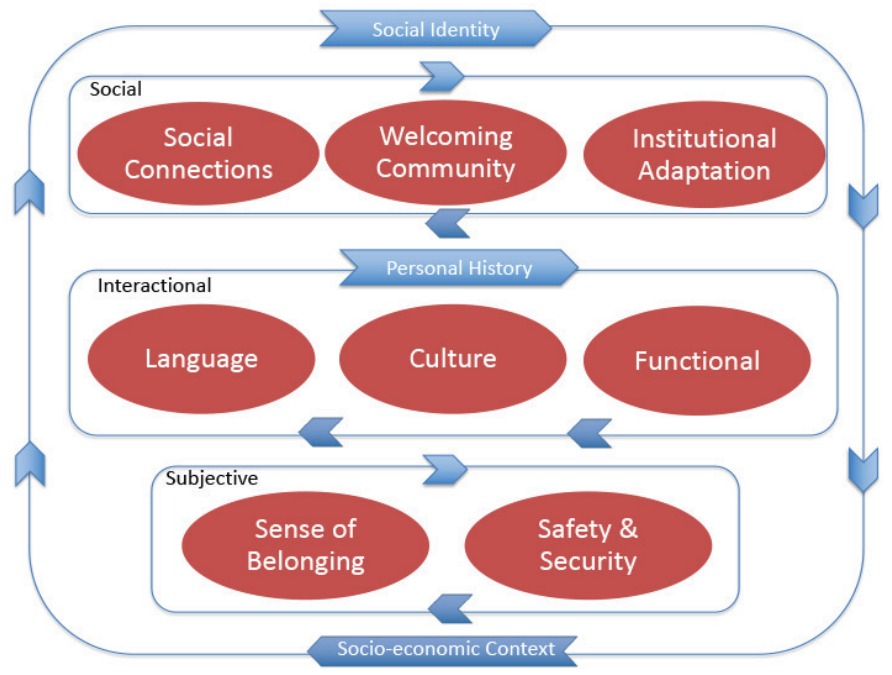

Figure 1. Holistic integration model

announcements, flyers, and direct requests at settlement agencies, community agencies, community events, food banks, and in buildings and neighbourhoods with high concentrations of Syrian refugees between April and July 2017. We interviewed a maximum of six participants from each household.

\section{Measures}

The national research team represented multiple sectors, including settlement, health care, mental health, and academia, and from a number of different disciplines, including social work, geography, psychology, family medicine, nursing, and psychiatry. Consistent with our commitment to an interdisciplinary community-based approach, peer researchers from the Syrian refugee community were involved from the beginning and throughout the project, including editing, revising, translating, and pilot testing survey materials, data collection, and data analysis.

Survey questions were developed collectively from categories identified in the holistic integration model. Priority was given to standardized scales that had validated Arabic versions. Professional English to Arabic translation was obtained for additional measures, followed by back translation by two bilingual Syrian Canadians to confirm accuracy. Surveys were discussed question by question with recently arrived Syrian newcomers, and unclear or discrepant terms were reviewed and modified. The project's (bilingual) research assistants conducted a final check to resolve any remaining issues with the translation and to ensure local relevance. The modified surveys were then piloted with twentyfour recent Syrian refugees, with changes again discussed 
and finalized with the national research team. The final version of the survey contained 245 questions. ${ }^{23}$ Only the measures being reported in this article are described below.

Sociodemographic and migration variables: These included questions about age, gender, religious affiliation, languages spoken at the time of interview, ethnicity, pre-migration occupation, marital status, number of children under eighteen years of age who are in Canada, and education.

Social-level variables: Measures of social networks were derived from the General Social Survey (Gss) ${ }^{24}$ and included questions about number of friends, closeness to friends, frequency of socializing, having friends from other ethnic communities, and closeness to friends from other communities. We added questions about number of relatives in Canada, friends from the Syrian community who had been in Canada for more than five years, and where they had met friends from other communities.

Interactional-level variables: These questions addressed self-assessed language skills, including how frequently they needed an interpreter for appointments and their self-rated ability to speak, understand, read, and write in English or French. ${ }^{25}$ Detailed questions were asked about the characteristics of employment, housing, health-care access, and educational access, which were modified from the Social Integration Inventory. ${ }^{26}$ For this article, we will focus on whether or not participants were employed, how they found employment, whether they had a family doctor, and satisfaction with their current housing, rated on a five-point scale.

Subjective variables: Questions about sense of belonging were also taken from the Gss, including belonging to one's neighbourhood, city, co-ethnic community in the city, and Canada. ${ }^{27}$ For brevity we focus here on sense of belonging to one's neighbourhood and sense of belonging to Canada. Responses were rated on a 1 to 5 scale, with higher scores indicating greater sense of belonging. Participants who were privately sponsored were also asked about how much they relied on their sponsors for information and help. Security was assessed through financial security; participants were asked if they ever had trouble making ends meet at the end of the month and had to ask for help.

Additional measures: Additional measures were included but will not be addressed here, for the sake of brevity. These include which social, health, and settlement services were used and satisfaction and comfort with these services, and self-rated health and mental health measures, including health behaviours, post-traumatic stress symptoms, depression, stress, and perceived control.

A coding table for all of these measures is available in appendix A.

\section{Procedures}

All participants provided informed consent prior to the interview and were paid for their participation. Surveys were collected using Quicktapsurvey on iPads through faceto-face interviews in Arabic. These took approximately sixty to ninety minutes each and were done primarily in participants' homes. Additional field notes documented researcher observations.

\section{Analysis}

All analyses were conducted using SPSS v. 24. All analyses were conducted using hierarchical linear modelling (HLM), with individuals nested within households, thereby clustering all results by family. A complete list of variables and coding is provided in appendix A. $P$ values are reported to facilitate interpretation of the models. However, these should not be taken to indicate significance of patterns in the population of Syrian refugees as a whole because the sample is not randomly selected; the $p$ values are being used descriptively. ${ }^{28}$ There were three levels of variables. Level 1 included the variables of sponsorship, city, and length of time in Canada, which reflect the general context of the participants and are likely to determine their social networks but also, because of the nature of refugee selection process, determine their socio-demographic characteristics. Level 2 included socio-demographic variables that are characteristics of the individual: namely age, gender, religious affiliation, education, length of time displaced, and self-assessed language knowledge at the time of testing-variables that can affect the ability to develop social networks. Level 3 variables reflected social networks: namely having relatives in Canada, number of friends from the established Syrian community, and having friends from other ethnic communities.

To describe the predictors of social networks, two models were tested. The first model included the Level 1 context variables. The second model included the Level 1 variables plus the Level 2 socio-demographic variables. Predictors of Relatives in Canada was an exception, as it was explored only in terms of the context variables. For integration outcome variables, three compounded models were tested: Models 1 and 2 as indicated, and Model 3, which included the Level 1 and Level 2 variables plus Level 3 social network variables. Models were compared using deviance statistics, with results reported only for the highest model showing an improved fit associated with a $p$ value of .05 or less, with the $p$ value indicating relative strength of improvement rather than inferential significance.

\section{Results}

The breakdown by type of sponsorship was: in British Columbia, Vancouver $(N=245 ; 186$ GAR, 48 PSR, 11 BVOR $)$ 
and Okanagan Valley ( $N=67$; 24 GAR, 22 PSR, 21 BVOR); in Ontario, Kitchener/Waterloo ( $N=139 ; 86$ GAR, 48 PSR, 5 BVOR), Toronto ( $N=531 ; 315$ GAR, 187 PSR, 39 BVOR), and Windsor ( $N=235$; 185 GAR, 45 PSR, 5 BVOR); and in Quebec, Montreal ( $N=694 ; 67$ GAR, 626 PSR, 1 BVOR). These numbers are equal to approximately $31 \%$ of the adult (eighteen and over) GARS and $8 \%$ of the adult PSRs who were intended to settle between 4 November 2015 and 31 July 2017 in the three cities in Ontario; $16 \%$ of the adult GARs and $18 \%$ of the adult PSRs destined to settle in Montreal, Quebec; and $41.6 \%$ of the adult GARs and $26 \%$ of the adult PSRs destined to Vancouver and the Okanagan (Kelowna, Vernon, and Kamloops) in British Columbia. ${ }^{29}$ The proportions suggest that PSRs were under-sampled relative to GARS in Ontario and BC.

Just under half of the participants were male $(48.8 \%)$ and over half were female $(51.1 \%)$. Participants ranged in age from eighteen to ninety and had been in Canada for up to thirtyfive months. A one-way ANOva on each variable showed that PSRS were significantly older and had been in Canada on average one month longer than GARs or BVors (see table 1). This is consistent with differences reported in the population of Syrian refugees arriving in the first wave of the Syrian initiative. According to IRCC, among those arriving in the first six months, $54 \%$ of GARs but $59 \%$ of PSRS were fifty years of age or older. Because Bvors were not part of our intended sample, they were represented in numbers too small to make meaningful comparisons and thus the BVORs are excluded from subsequent analyses, leaving a sample of 1,837 .

\section{Are There Differences by Type of Private Sponsorship?}

Among the privately sponsored participants in our national sample, more than two thirds $68.6 \%(n=659)$ were sponsored by faith organizations, $16.8 \%(n=161)$ were sponsored by family, and $9.7 \%(n=93)$ were sponsored by community organizations. Only $5 \%(n=48)$ of the sample were sponsored by a Group of Five ( $\mathrm{G}_{5}$ or Groupes 2-5 or G2-5 in Quebec). In Vancouver, $95.7 \%(n=45)$ were sponsored by faith organizations, whereas the remaining $5.2 \%(n<10)$ were sponsored by family or community organizations. In the Okanagan, $81.8 \%(n=18)$ were sponsored by faith organizations, whereas the remaining $18.2 \%(n<10)$ were sponsored by G5s. In Kitchener/Waterloo, 68.1\% $(n=32)$ were sponsored by faith organizations, whereas the remaining $31.9 \%$ ( $n=15)$ were sponsored by family, community organizations, or G5s. In Windsor, $86.7 \%(n=39)$ were sponsored by faith organizations, whereas the remaining $13.3 \%(n<10)$ were sponsored by family or community organizations. The pattern of sponsorship was more evenly distributed in Toronto, with $47 \%(n=85)$ sponsored by faith organizations, $26.5 \%$ $(n=48)$ sponsored by community organizations, $15.5 \%$
Table 1. Socio-demographic characteristics of Syrian refugee sample, by migration pathway

\begin{tabular}{llll} 
& GAR & PSR & BVOR \\
\hline Mean age & $35.9^{\mathrm{a}}$ & $41.0^{\mathrm{ab}}$ & $35.2^{\mathrm{b}}$ \\
$\quad$ SD & $(12.13)$ & $(14.7)$ & $(12.4)$ \\
$\begin{array}{l}\text { Mean time in Canada } \\
\quad \text { (months) }\end{array}$ & $12.7^{\mathrm{a}}$ & $13.9^{\mathrm{ab}}$ & $13.2^{\mathrm{b}}$ \\
$\quad$ SD & $(5.3)$ & $(5.6)$ & $(5.7)$ \\
\hline
\end{tabular}

Note: Means with shared superscripts differ significantly at the .05 level.

( $n=28)$ sponsored by family, and $11 \%(n=20)$ sponsored by G5s. Finally, in Montreal, 71.1\% $(n=440)$ were sponsored by faith organizations, $19.9 \%(n=123)$ were sponsored by family, $5.7 \%(n=35)$ were sponsored by community organizations, and $3.4 \%(n=21)$ were sponsored by G2-5s.

The characteristics of privately sponsored refugees differed by type of sponsorship, with G5s in particular showing differences from other sponsorship types (see table 2). This includes differences on characteristics that past research suggests are particularly relevant to integration outcomes such as employment (language ability, number of children), ${ }^{30}$ health (months displaced, months in a refugee camp), ${ }^{31}$ and community welcome (religion, particularly in light of the current wave of anti-Islamic attitudes) ${ }^{32}$ but not in terms of education and urban residence. Table 2 provides the means and frequencies for these characteristics for GARS, for PSRS overall, and then for the different types of PSRs. Comparison to the characteristics of the population in the first six months of the Syrian initiative suggests similar differences between GARS and PSRS overall. Namely, as in our own sample, IRCC data show much higher rates of university education among PSRS (31.6\%) than GARS (5.3\%), and higher self-reported knowledge of either English or French, with $18.2 \%$ of PSRS and $83.6 \%$ of GARs nationally reporting no knowledge of either of Canada's official languages. ${ }^{33}$

\section{Social Networks}

Social networks play an important role in refugee integration. ${ }^{34}$ The engagement of civic society is expected to promote integration for newcomers by increasing social support and access to social capital through sponsors. ${ }^{35}$ We therefore examine whether PSRS and GARs differ in the breadth of their social networks, in terms of relationships to (a) family; (b) established co-ethnic community members; (c) members of other communities; and (d) closeness of these relationships to other community members. 
Table 2. Socio-demographic characteristics by sponsorship

Private sponsorship by type

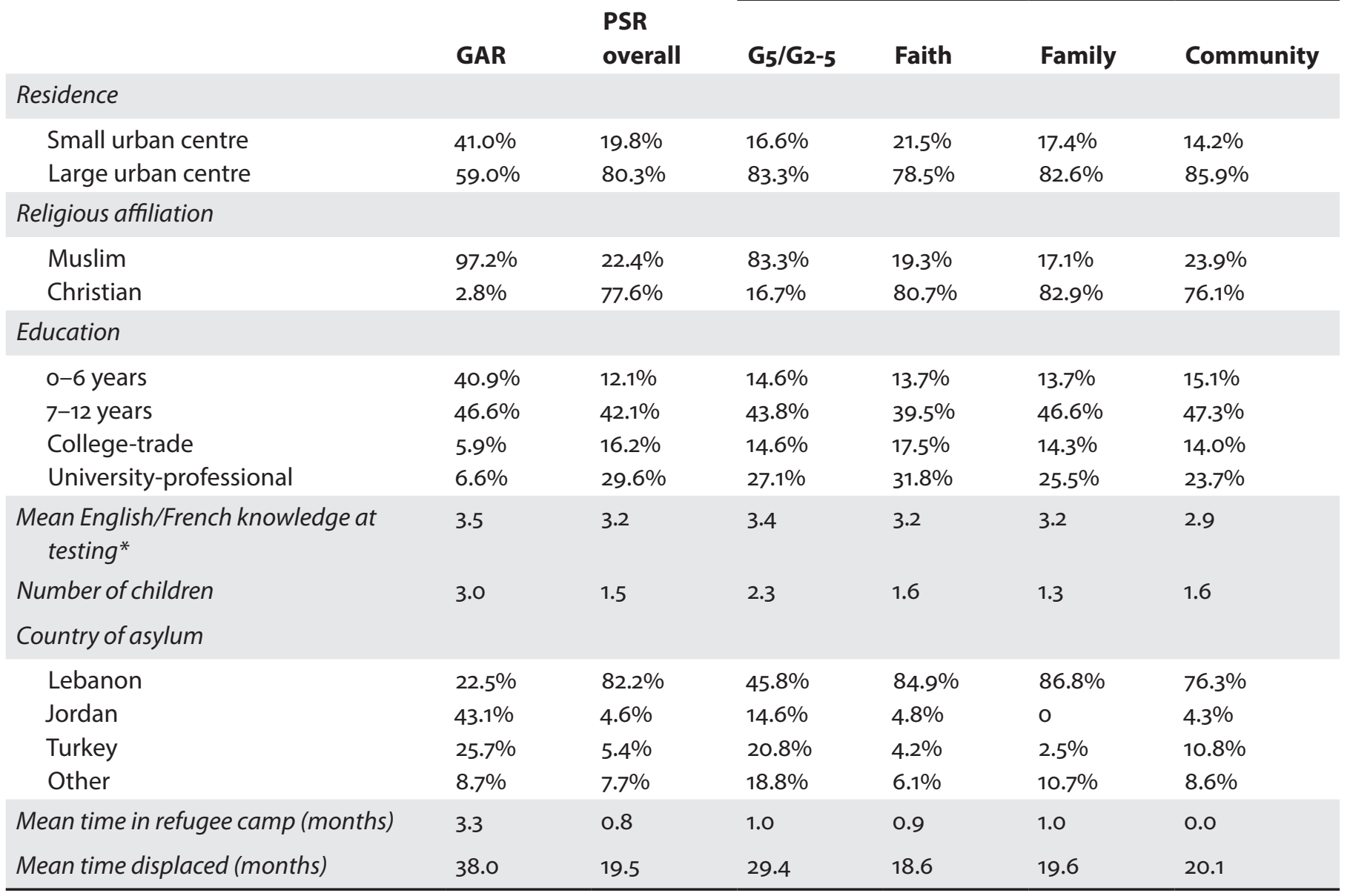

${ }^{*} 1$-none to 6 -excellent. This measure is self-assessed.

Relatives in Canada: For relatives in Canada, only the model with Level 1 variables was tested (see table 3). Not surprisingly, PSRS (80.3\%) were more likely to report having relatives in Canada than GARs (52.0\%). Percentage of GARS with relatives in Canada was particularly low in Okanagan (29.2\%) and then Windsor (41.6\%), but otherwise over half reported relatives in Canada (52\% to $59.7 \%$ ). Among PSRs, those in Vancouver were least likely to have relatives in Canada (63.8\%), followed by Okanagan (72.7\%) and Toronto (77.5\%). In the other cities, about $80 \%$ reported Canadian relatives (from $80.3 \%$ to $82.4 \%$ ).

Three variables measured friendship: friends in the established Syrian community, having friends from other communities, and closeness to friends from other communities.

Friends from the established Syrian community: The model with both Level 1 (city and sponsorship) and Level 2 (sociodemographic variables) predicted having more friends from the established Syrian community. PSRS reported more established Syrian friends (61.6\% reported at least one or more) than GARs (39.1\% reported at least one or more). Having a greater number of established Syrian friends was also positively predicted by greater length of stay in Canada, older age, being male, having a higher level of education, and better fluency in one of the official languages.

New friends in other ethnic communities: The model with both Level 1 and Level 2 was retained for new friends from other communities. Friends from other ethnic communities were reported by $55.5 \%$ of the sample overall and were more likely for those in Canada longer, who were younger, more highly educated, male, more fluent in self-assessed English/ French, and Muslim. Sponsorship did not predict friendships with people outside the Syrian community.

Closeness to friends from other ethnic communities: The higher order model with 2 Levels was retained for closeness 


\section{Table 3. Hierarchical models predicting social network variables}

\section{Relatives in Canada}

City

Sponsorship category (GAR o / PSR 1)

Length of time in Canada

Number of friends from the established Syrian community

City

Sponsorship category (GAR o / PSR 1)

Length of time in Canada

Age

Gender (female o / male 1)

Education

Official language fluency

Religion (Muslim o / Christian 1)

Length of displacement

Have new friends from other ethnic communities

City

Sponsorship category (GAR o / PSR 1)

Length of time in Canada

Age

Gender (female o / male 1)

Education

Official language fluency

Religion (Muslim o / Christian 1)

Length of displacement

Closeness to friends from other ethnic communities

City

Sponsorship category (GAR o / PSR 1)

Length of time in Canada

Age

Gender (female o / male 1)

Education

Official language fluency

Religion (Muslim o / Christian 1)

Length of displacement b SE P highest model

Improvement in fit of

$\begin{array}{ccc}-0.023 & 0.009 & 0.014 \\ 0.250 & 0.030 & 0.000 \\ -0.000 & 0.002 & 0.967\end{array}$

$X^{2}(6)=86.78, p<.001$

$\begin{array}{lll}-0.009 & 0.101 & 0.398\end{array}$

$0.153 \quad 0.043 \quad 0.000$

$0.008 \quad 0.003 \quad 0.003$

$0.005 \quad 0.001 \quad 0.000$

$\begin{array}{lll}0.080 & 0.022 & 0.000\end{array}$

$0.049 \quad 0.010 \quad 0.000$

$\begin{array}{lll}0.028 & 0.011 \quad 0.015\end{array}$

$\begin{array}{lll}-0.065 & 0.046 & 0.153\end{array}$

$\begin{array}{lll}-0.000 & 0.001 & 0.760\end{array}$

$X^{2}(6)=219.31, p<.001$

$\begin{array}{ccc}-0.006 & 0.010 & 0.524 \\ 0.055 & 0.040 & 0.168 \\ 0.011 & 0.002 & 0.000 \\ -0.004 & 0.001 & 0.000 \\ 0.076 & 0.020 & 0.000 \\ 0.030 & 0.010 & 0.002 \\ 0.074 & 0.011 & 0.000 \\ -0.201 & 0.043 & 0.000 \\ 0.000 & 0.001 & 0.779\end{array}$

$X^{2}(6)=81.352, p<.001$

$0.036 \quad 0.021 \quad 0.088$

$\begin{array}{lll}0.178 & 0.086 & 0.038\end{array}$

$\begin{array}{lll}0.012 & 0.006 & 0.036\end{array}$

$\begin{array}{lll}-0.002 & 0.002 & 0.395\end{array}$

$\begin{array}{lll}0.050 & 0.052 & 0.350\end{array}$

$\begin{array}{lll}-0.046 & 0.023 & 0.050\end{array}$

$\begin{array}{lll}0.031 & 0.030 & 0.261\end{array}$

$\begin{array}{lll}-0.190 & 0.093 & 0.043\end{array}$

$\begin{array}{lll}0.003 & 0.002 \quad 0.060\end{array}$ 
to friends from other ethnic communities. Participants were somewhat close to friends from other communities ( $M=2.5$ on a 4-point scale). PSRs reported being closer to these friends than did Gars. Participants were also closer to friends from other communities if they had been in Canada longer, had lower levels of education and were Muslim.

\section{How Useful Are Sponsors and Social Networks for Achieving Integration Goals?}

If sponsorship processes determine integration outcomes, then sponsorship and social networks should predict integration outcomes, even after pre-migration socio-demographic differences are taken into account. The impact of sponsorship and social networks on integration outcomes was addressed in two ways: (a) self-reported usefulness of sponsors, and (b) the extent to which integration outcomes related to employment, housing, health-care access, economic security, and sense of belonging are predicted by sponsorship category, socio-demographic variables, and social network variables.

How much did private sponsors help? Participants who were privately sponsored were asked how much they relied on their sponsors for information or help (not at all / a little / very much). Given that in some cities PSRs were sponsored almost exclusively by faith groups, cities were combined. As can be seen in figure 2 , the majority $(57.4 \%)$ of those sponsored by G5s reported relying on their sponsors a great deal. In contrast, those sponsored through the other paths varied in their reliance on their sponsors, with approximately equal numbers reporting relying on their sponsors very much, a little, or not at all.

Although resettled refugees can start working earlier, by month 13 in Canada, they are expected to find employment or move on to social assistance. A total of $64.3 \%$ of the GARs and $74.5 \%$ of the PSRs had been in Canada for thirteen months or longer. Among GARs, $11.4 \%$ had some form of employment at the time of the interview; for PSRS the proportion was $33.8 \%$. Among those employed, both groups identified co-ethnic friends as the most likely to have helped them find their job, with about one fifth having found their job on their own. Very few GARs (6.7\%) or PSRS (4.9\%) found jobs through employment agencies; community agencies were somewhat more helpful (GARS, 17.8\%; PSRs, 11.2\%). Sponsors were reported as the source of employment for only $12 \%$ of those PSRS who had found jobs (see figure 3 ).

Employment: The highest level model including Levels 1 and 2 plus the Level 3 social network variables fit better than either of the lower models with a $p$ of less than .05 and thus was retained. Current employment was predicted by sponsorship, such that PSRS were more likely to be employed than GARs, even when socio-demographic variables were in the model. Employment was also more likely for those who had been in Canada longer, were younger, male, Christian, or had relatives in Canada and friends in other ethnic communities (see table 4).

Trouble making ends meet: Model 3 with all variables was the best fit for having trouble making ends meet. In Model 3, older age and less language fluency were associated with having trouble making ends meet. Sponsorship did not predict this measure of financial difficulty when these other variables were taken into account.

Family doctor: Model 3 with all variables showed improved fit. Most participants reported having a family doctor, but this varied by city. In Vancouver only $79.4 \%$ had a family doctor, compared to $90.3 \%$ in Kitchener/Waterloo, $98.2 \%$ in Toronto and $100 \%$ in Okanagan. In Montreal only $54.9 \%$ of participants had a family doctor. Given the dominance of PSRS in this city, we looked at GARS and PSRS separately; only $33.3 \%$ GARS and $57.2 \%$ of PSRs had a family doctor. Having a doctor was also more likely for those who were older and were in Canada longer (see table 5).

Satisfaction with housing: Respondents were moderately satisfied with their housing. On a 5-point scale, with 1 representing not at all satisfied and 5 being very satisfied, both GARS and PSRs rated their satisfaction at 3.6. Although Model 3 was a better fit than either Model 1 or Model 2, no variables were significant predictors in this model suggesting relatively weak relationships. Model 2, which included only Levels 1 and 2, is therefore presented here. City was the only predictor of housing satisfaction achieving a $p<.05$. Participants were most satisfied in Windsor $(M=3.8)$ and Toronto $(M=3.7)$ and least satisfied in Vancouver $(M=3.4)$ and Kitchener/Waterloo $(M=3.3)$.

Sense of belonging: For sense of belonging to one's neighbourhood, Model 3 was retained. GARs reported a higher sense of belonging to their neighbourhood $(M=2.8)$ compared to PSRS $(M=2.6)$, and those in Windsor $(M=3.0)$ and Toronto $(M=2.9)$ reported higher sense of belonging to neighbourhood than those in other cities, where scores ranged between 2.5 and 2.7. Sense of belonging to neighbourhood was also somewhat higher among men $(M=2.3)$ than women $(M=2.2)$ and among those who were older (see table 6).

For overall sense of belonging to Canada, the model with all three levels was retained. Sense of belonging to Canada differed by city. It was lower among those in Montreal $(M=3.1)$ than the other cities, which ranged between 3.3 and 3.4. Sense of belonging to Canada was also higher among those with lower levels of education, who were male, and who had friends from other ethnic communities.

\section{Discussion}

As mentioned above, this study is guided by the holistic integration model. ${ }^{6}$ Here in our discussion we aim to place 
Table 4. Hierarchical models predicting employment and financial security

\begin{tabular}{|c|c|c|c|c|}
\hline & b & SE & $p$ & $\begin{array}{l}\text { Improvement in fit of } \\
\text { highest model }\end{array}$ \\
\hline Employment & & & & $x^{2}(3)=152.61, p<.001$ \\
\hline City & 0.024 & 0.008 & 0.002 & \\
\hline Sponsorship category (GAR o / PSR 1) & 0.162 & 0.032 & 0.000 & \\
\hline Length of time in Canada & 0.011 & 0.002 & 0.000 & \\
\hline Age & -0.006 & 0.001 & 0.000 & \\
\hline Gender (Female o / Male1) & 0.2339 & 0.018 & 0.000 & \\
\hline Education & -0.009 & 0.008 & 0.261 & \\
\hline Official language fluency & -0.006 & 0.009 & 0.486 & \\
\hline Religion (Muslim o / Christian 1) & 0.219 & 0.035 & 0.000 & \\
\hline Length of displacement & 0.001 & 0.001 & 0.062 & \\
\hline Relatives in Canada (No o / Yes 1) & 0.046 & 0.022 & 0.034 & \\
\hline Number of established Syrian friends & 0.011 & 0.020 & 0.593 & \\
\hline $\begin{array}{l}\text { Friends from other ethnic communities } \\
(\text { No o / Yes } 1)\end{array}$ & 0.068 & 0.020 & 0.001 & \\
\hline Trouble making ends meet & & & & $X^{2}(3)=348.77, p<.001$ \\
\hline City & 0.022 & 0.016 & 0.166 & \\
\hline Sponsorship category (GAR o / PSR 1) & -0.028 & 0.064 & 0.662 & \\
\hline Length of time in Canada & 0.006 & 0.004 & 0.106 & \\
\hline Age & 0.003 & 0.001 & 0.005 & \\
\hline Gender (Female o / Male 1) & 0.002 & 0.022 & 0.942 & \\
\hline Education & 0.008 & 0.012 & 0.480 & \\
\hline Official language fluency & -0.027 & 0.013 & 0.040 & \\
\hline Religion (Muslim o / Christian 1) & -0.021 & 0.067 & 0.759 & \\
\hline Length of displacement & 0.002 & 0.001 & 0.058 & \\
\hline Relatives in Canada (No o / Yes 1) & -0.056 & 0.032 & 0.083 & \\
\hline Number of established Syrian friends & 0.009 & 0.028 & 0.738 & \\
\hline $\begin{array}{l}\text { Friends from other ethnic communities } \\
\text { (No o/ Yes 1) }\end{array}$ & 0.028 & 0.029 & 0.328 & \\
\hline
\end{tabular}

our results on the differences between Syrian PSRS and GARS within the socio-political context in which they are resettling. Specifically, we discuss how Canadian refugee resettlement policy and the composition and political mobilization of earlier Syrian immigrant communities shaped the characteristics of refugees coming to Canada. We then look at how these characteristics (length of time displaced, religion, for example) may be influencing settlement outcomes, keeping in mind the local context (for example, local health or housing markets). Using the HIM allows us to go beyond individual outcomes to consider structural issues that may be addressed by changes in policy or practice.

Historically, private sponsorship in Canada has had two important elements. The first is the principle of additionality: refugees accepted into Canada as privately sponsored are in addition to at least the same number of refugees supported 


\section{Table 5. Hierarchical models predicting health care and housing outcomes}

\begin{tabular}{|c|c|c|c|c|}
\hline & $\mathbf{b}$ & SE & $p$ & $\begin{array}{l}\text { Improvement in fit } \\
\text { of highest model }\end{array}$ \\
\hline Have a family doctor & & & & $\begin{array}{l}X^{2}(3)=113.37 \\
p<0.001\end{array}$ \\
\hline City & 0.075 & 0.010 & 0.000 & \\
\hline Sponsorship category (GAR o / PSR 1) & -0.033 & 0.039 & 0.392 & \\
\hline Length of time in Canada & 0.008 & 0.002 & 0.000 & \\
\hline Age & 0.002 & 0.000 & 0.000 & \\
\hline Gender (Female o / Male 1) & -0.008 & 0.009 & 0.380 & \\
\hline Education & -0.008 & 0.0050 & 0.139 & \\
\hline Official language fluency & 0.004 & 0.005 & 0.429 & \\
\hline Religion (Muslim o / Christian 1) & -0.029 & 0.040 & 0.477 & \\
\hline Length of displacement & 0.001 & 0.000 & 0.228 & \\
\hline Relatives in Canada (No o / Yes 1) & 0.011 & 0.014 & 0.415 & \\
\hline Number of established Syrian friends & 0.002 & 0.012 & 0.885 & \\
\hline Friends from other ethnic communities (No o / Yes 1) & 0.015 & 0.012 & 0.213 & \\
\hline Satisfaction with housing & & & & $\begin{array}{l}X^{2}(6)=98.52 \\
p<0.001\end{array}$ \\
\hline City & 0.045 & 0.023 & 0.051 & \\
\hline Sponsorship category (GAR o / PSR 1) & 0.106 & 0.093 & 0.253 & \\
\hline Length of time in Canada & 0.002 & 0.005 & 0.703 & \\
\hline Age & 0.002 & 0.002 & 0.121 & \\
\hline Gender (Female o / Male 1) & 0.006 & 0.036 & 0.859 & \\
\hline Education & -0.013 & 0.019 & 0.484 & \\
\hline Official language fluency & 0.018 & 0.021 & 0.390 & \\
\hline Religion (Muslim o / Christian 1) & -0.095 & 0.099 & 0.338 & \\
\hline Length of displacement & 0.000 & 0.001 & 0.965 & \\
\hline
\end{tabular}

by the federal government for resettlement. It is this principle that allowed Canada to respond so quickly to the Syrian situation, exceeding its initial targets, and holding promise as a way to increase opportunities for the durable solution of resettlement. And yet the current Canadian government has set refugee resettlement targets for 2020 that defy the principle of additionality: 10,000 GARs versus 20,000 PSRS. ${ }^{37}$ The second principle of private sponsorship is that sponsors can name a specific person or family whom they wish to settle. ${ }^{3}$ Family members already in Canada often use private sponsorship as a means of family reunification through renewed support from their own sponsors or the SAH they know. They may also create a SAH or constituent group to become sponsors themselves. An evaluation study commissioned by IRCC found that $62 \%$ of PSRS surveyed reported that they were sponsored by a family member. ${ }^{39}$ Known colloquially as "the echo effect," 40 this decision to sponsor family members left behind clearly shapes the characteristics of those who are sponsored and the nature of their settlement experience by shaping the social context, as described in the 
HIM, but that may also ultimately have a strong influence on the newly arrived refugees' settlement outcomes through their moderating influence on other levels of integration. ${ }^{41}$

Canada had a small community of Syrian immigrants prior to the Syrian conflict. In 2011, 40,840 Canadian residents identified as having Syrian ethnicity. They lived primarily in Montreal (40\%) and Toronto (20\%); 57\% identified as Christian, $31 \%$ as Muslim, and $10 \%$ reported no religious affiliation. They were also highly educated, with $48 \%$ university graduates..$^{22}$ As the Syrian conflict escalated and became protracted, private sponsorship became a pathway for some residents of Syrian origin to bring relatives to Canada. The characteristics of the PSRS in our sample mirrored those of the more established Syrian Canadian community living in Canada prior to the war. Given that the population living in Canada was more likely to be Christian and highly educated than the average Syrian refugee, and given Syrian Canadians' active participation in private sponsorship, this partially explains the more pronounced differences between GARS and PSRs (along the lines of religious affiliation, language ability, and level of education) than normally observed.

The Canadian government actively sought to resettle those identified as the most vulnerable refugees through the GAR Program, further amplifying the differences between GARS and PSRS in this cohort. Families with disabilities, acute medical conditions, and single mothers with young children were among those who met the criteria for "vulnerability." Early results from the Canadian government's Rapid Impact Evaluation of the Syrian resettlement initiative support these assumptions. ${ }^{43}$ In the first wave of resettlement, the Syrian GARs had lower levels of education, less knowledge of official languages, and larger families than other cohorts of GARs. These differences between GARS and PSRS are seen in other refugee cohorts also, thus the importance of taking pre-migration differences into account when comparing integration outcomes between GARs and PSRs, 44 but especially so with the Syrian cohort. Caution is also important in comparing this cohort to others, given the unique nature of this initiative.

Our study identified other differences that to our knowledge have not been previously noted. GARs were displaced in a first country of asylum almost twice as long as PSRs, 38 months versus 19.5 months, suggesting longer exposure to the psychological and physical hardships of asylum. In this cohort there was also a large difference in the religion of GARs and PSRs, with almost all GARs being Muslim while three-quarters of the PSR sample was Christian, explained above as possibly being related to the presence of a relatively large and well-organized community of Christian Syrians in Montreal and Toronto. In the current climate of anti-Islamic discourse and attitudes, these differences may contribute to integration outcomes. Religion did contribute to some of the integration outcomes in this study; Muslim respondents were more likely to have friends from other ethnic communities and be closer to those friends, but less likely to have found employment. It will be important to explore further how religious identity is intersecting with other aspects of identity, social context, and migration pathways in shaping Syrian refugees' integration pathways.

This research also shows that privately sponsored refugees are not homogenous and need to be considered more closely in terms of types of sponsorship. While only $5 \%$ of our PSR population were sponsored by Groups of Five, there are distinctive features of this group compared to the other PSRS sponsored by faith, family, and community groups. During the Syrian resettlement, Groups of Five may have been less likely to be named than other privately sponsored refugees, although many are now trying to bring in family members of the first families they sponsored. 45 Their post-migration experiences also seemed to differ. Those sponsored by Groups of Five reported relying on their sponsors to a much greater extent than did the other types of PSRs. There is very limited research on the nature of private sponsors themselves, a recent paper by Macklin and colleagues being a notable exception. ${ }^{45}$ It suggests that these new sponsors were highly committed and motivated. More work is needed to understand this pattern and determine if it is replicated in other samples.

The breadth of our participants' social networks varied widely. Having friends in either the established Syrian community or among other communities was related to having spent more time in Canada but also to education, a better ability to speak one of the official languages, and being male. These findings are consistent with work on social exclusion among immigrants that finds women and those with lower language skills are more likely to be socially excluded. ${ }^{46}$ The importance of social inclusion for health and well-being is well established. This research contributes to the body of work that argues that additional steps need to be taken to ensure all members of newcomer communities can build community here.

The primary impact of social networks in this analysis emerged in the context of employment. Having employment was predicted both by having relatives in Canada and having friends from other ethnic communities. Similarly, co-ethnic friends were the most frequently mentioned pathway to finding employment. These findings underline the importance of social networks to accessing early employment and are consistent with qualitative reports on how refugees access employment in Canada. ${ }^{47}$ It also suggests the need to mobilize social networks to overcome social and structural barriers to employment. ${ }^{48}$ PSRs had more family and friends 
from the established Syrian community than did GARs, so this aspect of private sponsorship may help support the early advantage typically observed for PSRS in employment rates. Nonetheless, although previous research has shown that private sponsors can be key resources in finding employment through social connections, ${ }^{49}$ in our study, only a small proportion of our sample reported relying on their sponsors to find employment.

The second place where social networks had an impact was in a sense of belonging; having friends from other ethnic communities also predicted a sense of belonging to Canada, although not to one's immediate neighbourhood. This latter finding underscores the relationship identified in the HIM between a welcoming community, building social bridges, and a subjective sense of integration. Sense of belonging to one's neighbourhood, however, was predicted by the city one lives in, older age, being female, and being a GAR. The difference between these two forms of belonging may contrast an abstract sense of belonging with the strength of one's local social networks. Interestingly, sense of belonging to one's neighbourhood was also related to one's satisfaction with their housing, $r(1813)=.22, p<.001$, suggesting that physi$\mathrm{cal}$ and social environment may contribute to this sense of belonging.

Indeed, this study also illustrates the impact of the local context into which newcomers settle on key integration variables. Differences between cities include satisfaction with housing, sense of belonging to one's neighbourhood, and access to a family physician. These differences likely reflect local differences that affect all residents. For example, health-care access differences mirror findings on regional differences in the availability of family physicians. According to the Canadian Community Health Survey, Canadians in Ontario were among the most likely to have a primary care provider (90\%), whereas those in Quebec were the least likely (72.2\%)..$^{\circ}$ It is therefore not surprising that the sample in Quebec was least likely to have access to a family physician.
Health-care access may also reflect the extent to which specialized health-care services exist for recently arrived refugees. A study of the impact of a dedicated health clinic for GARS showed improved referrals and decreased wait times consistent with the authors' claims that the unique healthcare needs of recently arrived refugees are better addressed with specialized services. ${ }^{11}$ The findings on housing, however, are surprising, since Toronto is known to have a very difficult housing market, and yet participants there reported relatively positive views of their homes.

A number of limitations must be taken into account. Although the sample is large, it is not randomly selected, and those Syrian refugees who are experiencing the most hardship or isolation may be the most difficult to reach. Likewise, those who have had success in employment may have less time to participate in research, so it is unclear in what ways the sample might be biased relative to other Syrian refugees in these cities. The study also only recruited from six urban centres and thus cannot speak to resettlement experiences in rural regions.

In conclusion, the first wave of data for this project show that comparing GARS and PSRS is a fraught exercise, given the incommensurate profiles of each category. GARs are likely to be displaced almost twice as long as PSRs before emigrating to Canada. Furthermore, PSRs are not a homogeneous group: Groups of 5 resemble GARs more than other PSR sponsorship types. This article presents the first research we know that disaggregates private sponsorship into the various kinds of groups that exist. While family reunification is occurring because refugees can be specified by name, it is unclear how strong the echo effect is in terms of a kind of chain migration within the PSR Program. More research is needed to fill these gaps.

\section{Funding}

This work was funded by the Canadian Institute for Health Research grant number PJT-148960. 


\section{Appendix A. Dummy coded variables for hierarchal linear modelling (HLM)}

\section{Variable}

City

Sponsorship category

Length of time in Canada

Friends from the established Syrian community

Friends from other ethnic communities

Closeness to friends from other communities

Age

Education level

Length of displacement

Gender

Official language fluency

Religion

Relatives in Canada

Employment

Trouble making ends meet

Have a family doctor

\section{Coding}

$1=$ Kitchener

$2=$ Montreal

$3=$ Okanagan

$4=$ Toronto

$5=$ Vancouver

$6=$ Windsor

$1=$ Government-assisted refugee (GAR)

$2=$ Privately sponsored refugee (PSR)

Continuous variable

$1=$ Yes

$\mathrm{o}=\mathrm{No}$

$1=$ Yes

$\mathrm{o}=\mathrm{No}$

$1=$ Not at all

$2=$ A little close

$3=$ Mostly close

$4=$ Very close

Continuous variable

$1=$ No education / very low education-elementary school

$2=$ Low education-middle school

$3=$ Moderate education-high school

$4=$ High education-university degree

$5=$ Very high education-postgraduate studies

Continuous variable

$\mathrm{o}=$ Female

$1=$ Male

Continuous variable: mean score from 1-6 ( $1=$ Not at all; $6=$ Excellent) of current ability to speak and ability to understand French (Montreal) or English (all other sites)

Muslim $=0$

Christian $=1$

$1=$ Yes

$\mathrm{o}=\mathrm{No}$

$1=$ Yes

$\mathrm{o}=\mathrm{No}$

$1=$ No, never had to get assistance

$2=$ Yes, had to get assistance once or twice

$3=$ Yes, had to get assistance several times

$1=$ Yes

$\mathrm{o}=\mathrm{No}$ 


\section{Appendix A (continued)}

Variable

Satisfied with housing

Sense of belonging to neighbourhood

Sense of belonging to Canada

\section{Coding}

$1=$ Very unsatisfied

$2=$ Unsatisfied

$3=$ Neither satisfied or unsatisfied

$4=$ Satisfied

$5=$ Very satisfied

$1=$ Very weak

$2=$ Weak

$3=$ Strong

$4=$ Very strong

$1=$ Very weak

$2=$ Weak

$3=$ Strong

$4=$ Very strong

\section{Notes}

1 United Nations High Commissioner on Refugees (UNHCR), "Global Trends: Forced Displacement in 2017," 25 June 2018, http://www.unhcr.org/statistics/unhcrstats/5b27be547/ unhcr-global-trends-2017.html.

2 Xavier Devictor and Quy-Toan Do, "How Many Years Have Refugees Been in Exile?," policy research working paper created by World Bank Group, 2016, http://documents.worldbank.org/curated/en/549261472764700982/ How-many-years-have-refugees-been-in-exile.

3 UNHCR, "Global Trends."

4 UNHCR, "Global Refugee Sponsorship Initiative Promotes Canada's Private Refugee Sponsorship Model," 16 December 2016, https://www.unhcr.org/news/ press/2016/12/58539e524/global-refugee-sponsorship-initiative-promotes-canadas-private-refugee.html.

5 Jennifer Hyndman, William Payne, and Shauna Jimenez, "Private Refugee Sponsorship in Canada," Forced Migration Review 54 (2017): 51-9.

6 Immigration, Refugees and Citizenship Canada, "Syrian Refugees: Monthly IRCC Updates," last modified 11 July 2018, https://open.canada.ca/data/en/ dataset/o1c85d28-2a81-4295-9co6-4af792a7c209

7 Shauna Labman, "Private Sponsorship: Complementary or Conflicting Interests," Refuge 32, no. 2 (2016): 67-80.

8 UNHCR, Canada, Country Chapters - UNHCR Resettlement Handbook, February 2018, http://www.unhcr.org/3c5e55594 .pdf.

9 Immigration, Diversité et Inclusion Québec, "Learning About Collective Sponsorship," 31 October 2018, https:// www.immigration-quebec.gouv.qc.ca/en/immigrate-settle/humanitarian-immigration/collective-sponsorship/5steps/learning-sponsorships/index.html.
10 Sabine El-Chidiac, "The Success of the Privately Sponsorship Refugee System," Policy Options, July 2018, http://policyoptions.irpp.org/magazines/july-2018/success-privatelysponsored-refugee-system/; Nicholas Keung, "Sponsored Refugees Fare Better than Government Assisted Peers, Study Shows," Toronto Star, 31 October 2016, https://www. thestar.com/news/immigration/2016/10/31/sponsoredrefugees-fare-better-than-government-assisted-peersstudy-shows.html; Lori Wilkinson, "The Labour Market Experiences of Refugees in Canada," in Structural Context of Refugee Integration in Canada and Germany, edited by Annette Korntheuer, Paul Pritchard, and Débora B. Maehler, 93-8. GEsIs Series 15, 2017.

11 Linda K. Tip, Rupert Brown, Linda Morrice, Michael Collyer, and Matthew J. Easterbrook, "Improving Refugee Well-being with Better Language Skills and More Intergroup Contact," Social Psychology and Personality Sciences 10, no. 2 (2018): 144-51, doi:10.1177/1948550617752062.

12 Brigitte Suter and Karin Magnusson, Resettled and Connected? Social Networks in the Integration Process of Resettled Refugees (Malmö: Malmö Institute for Studies of Migration, Diversity and Welfare: Malmö University, 2015).

13 Michaela Hynie, "Canada’s Syrian Refugee Program, Intergroup Relationships and Identities," Canadian Ethnic Studies 50, no. 2 (2018): 1-12. doi:10.1353/ces.2018.0012; Judith Kumin, Welcoming Engagement: How Private Sponsorship Can Strengthen Refugee Resettlement in the European Union, Migration Policy Institute Europe, 2015, https:// www.migrationpolicy.org/research/welcoming-engagement-how-private-sponsorship-can-strengthen-refugeeresettlement-european.

14 Nicole Ives, Jill Witmer Sinha, and Ram Cnaan, "Who Is Welcoming the Stranger? Exploring Faith-Based Service 
Provision to Refugees in Philadelphia," Journal of Religion and Spirituality in Social Work: Social Thought 29 (2010): 71-89, https://doi.org/10.1080/15426430903479270; Wilkinson, "Labour Market Experiences," 93-8.

15 Michaela Hynie and Jennifer Hyndman, "From Newcomer to Canadian: Making Refugee Integration Work," Policy Options, May 2016, http://policyoptions.irpp.org/magazines/may-2016/from-newcomer-to-canadian-makingrefugee-integration-work/.

16 Immigration, Refugees and Citizenship Canada (IRCC), "Evaluation of the Resettlement Programs (GAR, PSR, BVOR and RAP)," July 2016, https://www.canada.ca/content/dam/ ircc/migration/ircc/english/pdf/pub/resettlement.pdf.

17 Wilkinson, "Labour Market Experiences", 93-8.

18 Jack Jedwab, “GARs vs PSRs: Explaining Differences in Outcomes for Recent Refugees to Canada," Canadian Diversity/ Diversité Canadienne 15, no. 2 (2018): 38-46.

19 Michaela Hynie, Ashley Korn, and Dan Tao, "Social Context and Social Integration for Government Assisted Refugees in Ontario, Canada," in After the Flight: The Dynamics of Refugee Settlement and Integration, ed. Morgan Poteet and Shiva Nourpanah, 183-227 (Newcastle: Cambridge Scholars, 2016).

20 Alastair Ager and Alison Strang, "Understanding Integration: A Conceptual Framework," Journal of Refugee Studies 21, no. 2 (2008): 166-91. https://doi.org/10.1093/jrs/feno16.

21 Stephen Castles, Maja Korac, Ellie Vasta, and Steven Vertovec, Integration: Mapping the Field (London: Home Office Immigration Research and Statistics Service, 2002), http://webarchive.nationalarchives.gov.uk/20110218135832/ http://rds.homeoffice.gov.uk/rds/pdfs2/rdsolr2803.doc; Jenny Phillimore and Lisa Goodson, "Making a Place in the Global City: The Relevance of Indicators of Integration," Journal of Refugee Studies 21, no. 3 (2008): 305-25, doi:10.1093/jrs/feno25; Alison Strang and Alastair Ager, "Refugee Integration: Emerging Trends and Remaining Agendas," Journal of Refugee Studies 23, no. 4 (2010): 589607, doi:10.1093/jrs/feq046; Hynie, "Canada's Syrian Refugee Program," 1-12.

22 Sunera Thobani, Exalted Subjects: Studies in the Making of Race and Nation in Canada (Toronto: University of Toronto Press, 2007); Himani Bannerji, The Dark Side of the Nation: Essays on Multiculturalism, Nationalism, and Gender (Toronto: Canadian Scholars' Press, 2000); GraceEdward Galabuzi, Canada's Economic Apartheid: The Social Exclusion of Racialized Groups in the New Century (Toronto: Canadian Scholars' Press, 2006).

23 The survey tool is available from the authors.

24 Statistics Canada, "General Social Survey 2008 Cycle 22: Social Networks Main Survey Questionnaire," 2018, http:// www23.statcan.gc.ca/imdb-bmdi/pub/instrument/5024_ Q1_V2-eng.htm\#a4.

25 Although we recognize the limitations of relying on selfassessed language skills, our study methods did not allow us to present more objective measures of language skills.
However, two different subjective measures, one inquiring about how frequently interpreters were needed, and one of self-rated ability, were highly correlated to each other (Spearman rho $=-.55, p<.001$ ), and both were to anticipated predictors of English/French-language skills, such as education levels (Language ability, rho $=-.39, p<.001$; Need interpreter, rho $=.49, p<.001)$; Aileen Edele, Julian Seuring, Cornelia Kristen, and Petra Stanat, "Why Bother with Testing? The Validity of Immigrants' Self-Assessed Language Proficiency," Social Science Research 52 (2015): 99-123, http://dx.doi.org/10.1016/j.ssresearch.2014.12.017.

26 Michaela Hynie, An Impact Evaluation of Client Support Services for Government Assisted Refugees, Final report for YMCA and Citizenship and Immigration Canada, 2014.

27 Statistics Canada, "General Social Survey 2008."

28 Valentin Amrhein, David Trafimow, and Sander Greenland, "Inferential Statistics as Descriptive Statistics: There Is No Replication Crisis If We Don't Expect Replication," American Statistician 73, no. S1 (2019): S262-70. doi:10.7287/peerj. preprints.26857V4.

29 Numbers of adult refugees per city are calculated from the total number of adult refugees destined to each province during this time period, multiplied by the percentage of refugees destined to each city during this time. It may underestimate the number of adults, since single adults may be more likely to be settled in cities than rural regions, and large families may be more likely to be settled in rural regions. It also does not take into account secondary migration patterns; Immigration, Refugees and Citizenship Canada (IRCC), "Syrian Refugees: Monthly IRCC Updates," 2017, https://open.canada.ca/data/ dataset/o1c85d28-2a81-4295-9co6-4af792a7c209.

30 Susan Li, Belinda Liddell, and Angela Nickerson, "The Relationship between Post-Migration Stress and Psychological Disorders in Refugees and Asylum Seekers," Current Psychiatry Reports 18, no. 9 (2016): 82, doi:10.1007/ s11920-016-0723-0; Kenneth Miller and Andrew Rasmussen, "The Mental Health of Civilians Displaced by Armed Conflict: An Ecological Model of Refugee Distress," Epidemiology and Psychiatric Sciences 26, no. 2 (2016): 129-38, doi:10.1017/S2045796016000172.

31 Marija Bojic, Dean Ajdukovic, Stephen Bremner, Tanja Franciskovic, Gian M. Galeazzi, Abdulah Kucukalic, Dusica Lecic-Tosevski et al. "Factors Associated with Mental Disorders in Long-Settled War Refugees: Refugees from the Former Yugoslavia in Germany, Italy and the UK," British Journal of Psychiatry 200 (March 2012): 216-23, https:// doi.org/10.1192/bjp.bp.110.084764; Matthew Porter and Nick Haslam, "Predisplacement and Postdisplacement Factors Associated with Mental Health of Refugees and Internally Displaced Persons: A Meta-analysis," Journal of the American Medical Association 294, no. 5 (September 2005): 602-12, https://doi.org/10.1192/bjp.bp.110.084764.

32 Kirk Bansak, Jense Hainmueller, and Dominik Hangartner, "How Economic, Humanitarian, and Religious Concerns 
Shape European Attitudes toward Asylum Seekers," Science 354, no. 6309 (2016): 217-22. doi:10.1126/science.aag2147; Ipsos, Global Views on Immigration and the Refugee Crisis, 2016, https://www.ipsos.com/sites/default/files/2016-08/ Immigration_and_Refugees-July_2016.pdf.

33 Immigration, Refugees and Citizenship Canada, "Rapid Impact Evaluation of the Syrian Refugee Initiative," December 2016, http://www.cic.gc.ca/english/resources/evaluation/pdf/evaluation-syrian-refugee-initiative.pdf.

34 Jill Hanley, Adnan Al Mhamied, Janet Cleveland, Oula Hajjar, Ghayda Hassan, Nicole Ives, Rim Khyar, and Michaela Hynie, "The Social Networks, Social Support and Social Capital of Syrian Refugees Privately Sponsored to Settle in Montreal: Indications for Employment and Housing during their Early Experiences of Integration," Canadian Ethnic Studies 50, no. 2 (2018): 123-48; Michaela Hynie, Valorie A. Crooks, and Jackeline Barragan, "Immigrant and Refugee Social Networks: Determinants and Consequences of Social Support among Women Newcomers to Canada," Canadian Journal of Nursing Research 43, no. 4 (2011): 26-46.

35 Labman, "Private Sponsorship," 67-80; Kumin, Welcoming Engagement.

36 Hynie, Korn, and Tao, "Social Context and Social Integration."

37 Immigration, Refugees and Citizenship Canada, 2017 Annual Report to Parliament on Immigration, 2017, https:// www.canada.ca/en/immigration-refugees-citizenship/corporate/publications-manuals/annual-report-parliamentimmigration-2017.html.

38 Immigration, Refugees and Citizenship Canada, Guide to the Private Sponsorship of Refugees Program, 2015, https:// www.canada.ca/en/immigration-refugees-citizenship/corporate/publications-manuals/guide-private-sponsorshiprefugees-program; Labman, "Private Sponsorship," 67-80.

39 Jedwab, "GARS vs PSRs," 38-46.

40 Ashley Chapman, "Private Sponsorship and Public Policy: Political Barriers to Church-Connected Refugee Resettlement in Canada," Citizens for Public Justice (2014), https:// cpj.ca/private-sponsorship-and-public-policy/.

41 Jedwab, “GARS vs PSRs," 38-46.

42 Citizenship and Immigration Canada, "Population Profile: Syrian Refugees”, 2015, https://www.cpa.ca/docs/File/Cultural/EN\%20Syrian\%2oPopulation\%2oProfile.pdf.

43 Immigration, Refugees and Citizenship Canada, Guide to the Private Sponsorship.

44 Jedwab, "GARS vs PSRs," 38-46.

45 Audrey Macklin, Kathryn Barber, Luin Goldring, Jennifer Hyndman, Anna Korteweg, Shauna Labman, and Jona Zyfi, "A Preliminary Investigation into Private Refugee Sponsors," Canadian Ethnic Studies 50, no. 2 (2018): 35-57.

46 Usha George and Ferzana Chaze, "Tell Me What I Need to Know: South Asian Women, Social Capital and Settlement," Journal of International Migration and Integration 10, no. 3 (2009): 265-82.
47 Hynie, Korn, and Tao, "Social Context and Social Integration."

48 Harald Bauder, "Habitus Rules of the Labour Market and Employment Strategies of Immigrants in Vancouver," Canada, Social \& Cultural Geography 6, no. 1 (2005): 81-97, doi :10.1080/1464936052000335982.

49 Jessica Eby, Erika Iverson, Jennifer Smyers, and Erol Kekic, "The Faith Community's Role in Refugee Resettlement in the United States," Journal of Refugee Studies 24, no. 3 (2011): 586-605.

50 Statistics Canada, "Primary Health Care," 2015, https:// www150.statcan.gc.ca/n1/pub/82-625-x/2017001/ article/14769-eng.htm.

51 Josephine McMurray, Katherine Breward, Michael Breward, Rob Alder, and Neil Arya, "Integrated Primary Care Improves Access to Healthcare for Newly Arrived Refugees in Canada," Journal of Immigrant and Minority Health 16 (2014): 576-85, doi:10.1007/s10903-013-9954-X

Michaela Hynie is a professor in the Department of Psychology at York University. The author may be contacted at mhynie@ yorku.ca.

Susan McGrath is a professor emerita in the School of Social Work at York University. The author may be contacted at smcgrath@yorku.ca.

Jonathan Bridekirk is a PhD student in the Department of Psychology at York University. The author may be contacted at jonathanbridekirk@gmail.com.

Anna Oda is the refugee integration and long-term health outcomes project coordinator at York University. The author may be contacted at annaoda@yorku.ca.

Nicole Ives is an associate professor and director of the Bachelor of Social Work Program at McGill University. The author maybecontacted at nicole.ives@mcgill.c.

Jennifer Hyndman is a professor and director of the Centre for Refugees Studies, York University. The author may be contactedatjhyndman@yorku.c.

Neil Arya is a family physician in Kitchener, on, and assistant clinical professor in family medicine at McMaster University. The author may be contacted at narya@uwaterloo.ca.

YogendraB. ShakyaisaseniorresearchscientistatAccess Alliance. The author may be contacted at yshakya@accessalliance.ca.

Jill Hanley is an associate professor in the School of Social Work at McGill University. The author may be contacted at jill .hanley@mcgill.ca.

Kwame McKenzie is the CEO of the Wellesley Institute. The author may be contacted at kwame@wellesleyinstitute.com. 
Syria.lth (Alyaa Ibrahim, Adela Colhon, Adnan Al Mhamied, Ahmed Bayoumi, Anas Issa, Anna Oda, Anneke Rummens, Arman Hamidian, Ben Kuo, Branka Agic, Carolyn Beukeboom, Chris Friesen, Christina Clark-Kazak, Dania Kallas, Faida Abu-Gazaleh, Farah Ahmad, Ghayda Hassan, Helen Ala Rashi, Huda Bukhari, Janet Cleveland, Jennifer Hyndman, Jill Hanley, Jonathan Bridekirk, Kashmala Qasim, Kathy
Sherrell, Kwame McKenzie, Lamiaa Al Olabi, Lana Saad, Lina Abdullah, Mahi Khalaf, Marcela Diaz, May Massijeh, Michaela Hynie, Michele Millard, Mona Awwad, Monira Dali, Oula Hajjar, Rabih [Fakhri] Jamil, Rana Mohammad, Rana Nourallah, Riham Al-Saadi, Rim Khyar, Rosemary Yachouh, Susan McGrath, Yogendra Shakya, and Youssef Demashkieh) 